\title{
Dutch public affairs professionals in the national and European arena: A smart mix of skills, attitude, and knowledge competences
}

\author{
Edward L. Figee | Jordy F. Gosselt | Paul C.J. Linders | Menno D.T. de Jong
}

Department of Communication Science, Faculty of Behavioural, Management and Social Sciences, University of Twente, Enschede, The Netherlands

Correspondence

Edward L. Figee, University of Twente, Department of Communication Science, Faculty of Behavioural, Management and Social Sciences, Enschede, The Netherlands. Email: e.l.figee@utwente.nl

\begin{abstract}
Although the profession of public affairs (PA) is increasingly important for organizations, relatively little is known about the range of competences PA professionals need. This article presents a qualitative study among 41 experienced Dutch PA professionals and practitioners, who were interviewed about the competences needed in regional and local PA. The results show that a combination of skills-related, attitudinal, and knowledge-related competences is needed. Skills-related competences involve two broad domains: politics and communication. Attitudinal competences comprise the almost paradoxical qualities of authentic professionalism and flexibility. Knowledge-related competences comprise political and communicative knowledge. These competences are used in a delicate process of swapping, depending on the situation of the very moment and the PA file at hand. Every competence may be of decisive importance. The PA professional is a silent diplomat.
\end{abstract}

\section{1 | INTRODUCTION}

Public affairs (PA) is gaining ground in the public sector in the Netherlands. Traditionally, governmental organizations would find themselves on the receiving end of PA activities, but nowadays, many governmental organizations recognize that PA activities can be a useful means for them to promote their interests and get things done. In particular, regions and municipalities realize that PA can help them to reach the national and European political arenas and draw attention to regional and local issues and interests. PA is a managerial tool that can be used to influence processes of political decision-making in the national and European arena (Marx, 1990; Van Schendelen, 2013, p. 15-24, 60).

The PA profession that these decentralized governmental bodies are entering is hard to demarcate (Harris \& Moss, 2001a, 2001b; Schuler, 2002). In general terms, PA may be described as "a strategic management discipline, directed to the political, administrative realm the organization is functioning in or is going to function in" (Linders \& De Lange, 2003, p. 17). According to McGrath, Moss, and Harris (2010) and Van Schendelen (2013, p. 15-24), the problems of demarcating PA can be attributed to ongoing dynamics in society, which are continuously modeling the public and private sectors (Van de Donk, 2014).

Earlier research shows that the effective use of PA by decentralized governments involves many challenges, such as preparing the home organization for the use of PA (Figee, Gosselt, Linders, \& De Jong, 2017a); forging regional and public-private collaborations (Figee,
Gosselt, Linders, \& De Jong, 2017b); and accessing the complex, highly competitive, and not always susceptible national and European political arenas (Figee, Gosselt, Linders, \& De Jong, 2016). Considering that PA professionals have to act on various stages with highly relevant but often vaguely demarcated objectives, it is no wonder that questions arise about the expertise of PA professionals. What are the competences PA professionals must bring to the job?

In an earlier study (Figee, Gosselt, Linders, \& De Jong, 2017c), we addressed this question using a survey among PA professionals. The results showed a wide variety among PA professionals, both in educational background and in competences, and a long list of competences PA professionals must develop. In this article, we take a qualitative approach to answer the question more in detail while focusing on the context of regional and local PA. We interviewed prolific and seasoned PA professionals and practitioners, who all had participated in the domain of regional and local PA in various roles, about the competences that are crucial for the PA professional.

\section{2 | EARLIER RESEARCH INTO PA AND PR COMPETENCES}

Earlier research provides some clues for an inventory of PA competences. Fleisher (2007) argued for the need of a PA body of knowledge and put the identification, description, and measurement of PA 
competences high on the academic research agenda. Still, most of the work on professional competences involves the adjacent public relations (PR) discipline.

Sha (2010) described a large-scale survey among PR practitioners focusing on their daily practices and distinguished the following competences:

- research, planning, implementation, and evaluation of PR programs,

- PR ethics and legal issues,

- application of communication models and theories to PR work projects,

- incorporation of business literacy skills into PR duties,

- management skills and issues,

- crisis communication management,

- media relations,

- use of information technology and new media channels,

- application of historical knowledge of the field of PR to work projects, and

- use of advanced communication skills.

Three things stand out when considering this listing from a PA perspective. First, the PR profession seems to be defined as a typical and traditional communication discipline, whereas PA professionals often operate at the crossroads of communication and governance/politics (Figee et al., 2016, 2017a). Second, the strategic aspects of the daily work of PA professionals, maneuvering between their home organization and various political arenas, do not seem to be satisfactorily covered by these competences. Third, competences seem to be defined as academic subdomains rather than as requirements of the professionals.

Flynn (2014) conducted a literature review of PR competences, broadening the gamut proposed by Sha (2010) and directing the PR competencies even more in the direction of more or less general academic competences:

- information and communication technology competency,

- cultural competence,

- communication skills,

- ethics,

- strategic planning/strategizing,

- business acumen,

- analytic/evaluation/measurement competency,

- leadership,

- crisis management, and

- relationship management/building competency.

Davidson (2015), studying PA in the context of PR scholarship and referring to De Lange and Linders (2006), argued that PA "has been observed as higher status strategic work [...] and that specialists are more than 'mere technicians' but professionals who wield influence in shaping internal and external realities for an organisation" (p. 615) PR and PA should be separated, Davidson concluded, referring to the ongoing debate concerning the definition of PA, which "may be still in a state of flux" (p. 615).

Gregory (2008) conducted qualitative research into the competences of senior communication professionals in the private and public sectors. Her results seem to reflect the strategic and political competences needed in PA practice more than the aforementioned studies. She found the following 10 core competences for professionals in the public sector:

- understanding the bigger picture,

- consulting and involving,

- managing under pressure,

- upholding the reputation of the service,

- presenting and communicating,

- taking action,

- building strong relationships,

- formulating strategies and concepts,

- persuading and influencing, and

- creating and innovating.

Although formulated in rather general terms, these competences appear to incorporate both the strategic and the hands-on work involved in PA practice. However, the competences are only implicitly related to knowledge, attitudes, and skills of the PA professional.

More specifically, McGrath (2006) conducted extensive research into the personal competences for "the ideal lobbyist." According to this study, a lobbyist should be a good listener and observant. He also mentions courtesy, relationship skills, honesty, and integrity/credibility as important personal traits. It should be noted that this study was limited to one aspect of PA (lobbying) and one competence domain (personal characteristics).

The most comprehensive study into PA competences so far was by Figee et al. (2017c), who conducted a survey among Dutch PA professionals about relevant competences. They distinguished knowledge-, attitude-, and skills-related competences and operationalized each in many different aspects (see Table 1). The results showed that all competences were considered to be important or very important by the PA professionals. Interestingly, the PA professionals were often more critical of their own qualities than of the importance of the competences.

Overall, the previous research shows that there are many competences involved in the PA profession. It is hard to differentiate the crucial from the less important competences. That is why we complement these findings with a qualitative study into the PA competences spontaneously mentioned by prolific PA professionals and practitioners.

\section{3 | METHOD}

To answer the research question, a series of interviews were held with seasoned PA professionals and practitioners working for and in 
TABLE 1 Competences distinguished by Figee et al. (2017c)

\begin{tabular}{ll} 
Competence cluster & Subcategories \\
\hline Knowledge & $\begin{array}{r}\text { Knowledge about national and international societal developments; knowledge about processes in decision-making in the public } \\
\text { sector on the national/regional/local/EU level; professional knowledge; knowledge about new media; knowledge about media } \\
\text { logics; knowledge about the opinions in the home organization about PA }\end{array}$ \\
$\begin{array}{l}\text { Reliability; adaptability; authenticity; personal involvement with PA files; critical attitude; withstanding stress; loyalty toward the } \\
\text { interests of the home organization; reputation management by customer- or civilian-oriented behavior; acceptance of irregular } \\
\text { working hours; integrity }\end{array}$ \\
$\begin{array}{l}\text { Expertise in long-term (strategic) and short-term (tactic) activities; social expertise; networking; empathy; ability to acquire support } \\
\text { for current PA files; persuasive power; ability to bear sole responsibility; pragmatism; oral and written language skills; ability to } \\
\text { analyze data; seniority; ability to influence media; constructive (win-win) and competitive (win-lose) negotiation skills }\end{array}$
\end{tabular}

governmental organizations, with ample experience on the decentral, national, and European levels. These interviews served multiple purposes. In addition to the competences reported in this article, they also addressed the workings of the national and European arena (Figee et al., 2016), the relationship to the home organization (Figee et al., 2017a), and the external collaborations required for PA (Figee et al., 2017b).

\section{1 | Participants}

The recruitment of prolific PA professionals and practitioners involved snowball sampling, described by Noy (2008, p. 340) as "effective in the research of organic social networks." In total, 41 participants were interviewed. The group consisted of 17 PA professionals and 24 PA practitioners. The 17 PA professionals worked in the public sector (e.g., highly placed officials entrusted with PA accounts) or in the private sector (e.g., stand-alone PA consultants or employees of PA agencies or companies with substantial links to local or regional governments). The 24 PA practitioners worked for municipalities and provinces, such as mayors, aldermen, city clerks, local and regional civil servants temporarily or indirectly connected with PA (municipals and provinces), Commissioners of the King (provinces), Deputies (provinces), Members of Parliament (with outspoken regional roots), and Members of the European Parliament (also with outspoken regional roots).

Most of the PA practitioners had occupied more than two of the mentioned functions, often for many years. For instance, they may have started their career as alderman or mayor, then Commissioner of the King, then $M(E) P$, then minister or state secretary, or the other way around. Some of the interviewed persons-of local and regional authorities-were or had been also a member of a local or regional council. Summing up all functions, in figures, 32 functions were at the municipal level (also regional in case of municipal cooperation), 26 functions at the provincial level (also regional in case of provincial cooperation), 23 functions at the national level, and 12 functions at the European level; in total 93 different functions. The age of the interviewees ranged between 40 and 60 years; 34 of the 41 interviewees were male.

\section{2 | Interview protocols}

The interview protocols had an open-ended nature and gave the participants the opportunity to elaborate on their professional experiences. Each interview started with questions about the political and administrative landscape of the national and European arena. Then questions followed about the home organization, related to internal and external aspects of organizing PA, and about competences of the PA professional and the PA practitioner. In all three parts of the interviews, participants talked a lot about PA competences.

The interviews were held in a location chosen by the participants: mostly in municipal offices, provincial offices, company offices, offices of the Dutch House of Parliament, the national press-office, or elsewhere in The Hague or Brussels. As many of the participants had prolific positions in society, and the topics discussed could involve political sensitivity, absolute confidentiality and anonymity was guaranteed to them. In all interviews, participants felt sufficiently safe to talk very openly about their views and experiences. All interviews lasted about 90 min and were audio recorded (with the participants' permission). The interviews with the last participants started to show repeating elements in the data.

\section{3 | Coding and analysis}

All interviews were transcribed verbatim. The first step in the analysis was that the first author derived key phrases from the interview transcripts. This led to a total of 1,003 key phrases. These key phrases were then checked against the interview transcripts by three independent coders. Of the 1,003 key phrases, $76 \%$ were confirmed without any changes. The remaining key phrases needed discussion, and eventually, some of them were (partially) reformulated, some were split into different key phrases, and some key phrases were added. The result was a total of 1,050 key phrases.

The next step involved the identification of competence-related key phrases. Two independent coders categorized all 1,050 key phrases using the four main categories (national and European arena, home organization, external collaboration, and competences). They reached a Cohen's kappa of .72. This resulted in a total of 110 key phrases that related to PA competences. A closer inspection of the 110 original key phrases showed that most of them in fact referred to several competences at the same time. We decided to separate them, which led to a total of 457 competence statements.

The 457 competence statements were first categorized into knowledge, skills, and attitudinal competences. Then, using principles of grounded theory, specific subcategories emerged. This resulted in six categories of competences. Two coders independently coded a random sample of 113 competence statements and reached a Cohen's kappa of .76. After reaching agreement about initially different codings and adjusting the code descriptions, the first author coded the remaining competence statements. 
Skills-related competences were defined as the technical and strategic abilities PA professionals need in their work. Two subcategories emerged here: political skills (abilities to develop long- and short-term PA operations) and communicative skills (abilities to effectively compose PA messages and manage interactions and relationships). Attitudinal competencies were defined as dispositional characteristics that PA professionals need in their work. Two subcategories emerged: authentic professionalism and flexibility. Knowledge-related competences were defined as the factual knowledge and understanding PA professionals need in their work. Two subcategories of knowledgerelated competences emerged from our data: political knowledge (about the functioning of political arenas) and communicative knowledge (about [new] media and media logics and PA as a discipline).

\section{4 | RESULTS}

Table 2 gives an overview of the distribution of the 457 competence statements over the three competence clusters and the six subcategories. On the basis of these figures, some interesting observations can be made. First, skills-related competences appeared to be most frequently mentioned (242 key phrases), followed by attitudinal competences (130 key phrases), and knowledge-related competences (85 key phrases). Second, within the knowledge cluster, political competences play a dominant role, whereas communicative competences outnumber the political competences in the skills cluster. We will qualitatively discuss the results per competence cluster below.

\section{1 | Skills-related competences}

Within the important cluster of skills-related competences, a distinction could be made between political and communicative skills.

Regarding political skills, participants first and foremost mentioned a general political sensitivity ("political antenna and political intuition") that PA professionals need. This was specified in various ways. PA professionals should be able to "think proactively, conceptually, and out of the box" to develop political pressure at the right moments. They must be "analytic and strategic, able to negotiate, and distinguish headlines from sidelines." They can "think on abstract levels" and position themselves in the role of "permanent advisor," for instance by creating reciprocity in the national and European arena ("bringing in something and getting back something") and activating their local and regional contacts by "being creative and original." In the words of one of the participants, "It is essential that the PA professional can judge and review PA

TABLE 2 Distribution of key phrases ( $N=457)$ over competence clusters and subcategories

\begin{tabular}{ll} 
Competence cluster & Subcategories \\
\hline Skills (242) & $\begin{array}{l}\text { Political (85) } \\
\text { Communicative (157) }\end{array}$ \\
\hline Attitude (130) & $\begin{array}{l}\text { Authentic professionalism (71) } \\
\text { Flexibility (59) }\end{array}$ \\
\hline Knowledge (65) & Political (45) \\
& Communicative (20)
\end{tabular}

files, in order to look for stakeholders who may be helpful to develop political processes of influencing."

Political skills are especially important at "peak moments in the political arenas," when messages come together. This refers to a specific PA competence, namely, "being in control of continuity by matching and merging PA messages." At such moments, only professionals who have the overview will recognize relevant crossconnections, "either putting them in the spotlight, or keeping them in the shadow." The PA professional is not a politician, but should have similar competences.

The PA professional must be able to look beyond the issues of the day, [...] putting PA issues in a short-list in order to start initiatives at the right moment with the right information, knowing that the shortest distance between two points is not always a straight line, [...] recognizing iterative processes [...] Balancing issues and interests is more than knowing facts and figures [...] It is the ability to create continuity.

Regarding communicative skills, many different aspects were mentioned. The most prominent competences involved the handling of large amounts of (complex) information, crafting messages, building and maintaining relationships, and connecting people:

The PA professional is a connector of relations and $a$ collector of information, a "liaison-officer," and a multiform networker, contacting people easily and maintaining relations, boosting relevant initiatives, keeping formal affairs informal, with the ability to listen.

Some participants explicitly connected the information handling and the relationship building with each other. In their view, connecting means "being a sparring partner by serving politicians and civil servants, and by sharing thoughts, opinions and insights." PA professionals may to some extent be guiding their political and administrative contacts, providing them with information about the political arenas. As one participant said,

In PA operations, the PA professional is the linking pin, controlling not only external but also internal relationships, adaptive for others' specifications and interests, conscious of political and regional surroundings, [...] finding the right tone of voice [...], and willing to share information, also in the home organization with relevant colleagues at relevant policy levels.

Regional and local PA professionals must have specific antennas to maintain cooperation with external parties, despite the weight of their home organization's interests and despite the burden of possibly opposite interests of cooperation partners:

They must be able to accept and respect opposite opinions of stakeholders and nevertheless maintain the relationship [...] informing their partners in PA operations about the goals of their operations, or explaining why they cannot participate in an operation. 
Regarding networking skills, participants mentioned many different characteristics, referring to "a highly developed social ability, to be accepted at all levels, at the pantry and the coffee-corner as well in the boardroom, gaining respect and authority." The professional is, in the words of a participant,

... creating entrances to the regional private sector [...] in governmental, societal and educational institutes, in the national and European arenas, [...] they should be easily accessible [...], open for cooperation, [...] They are multilanguage speaking, [...] love to be among the people [...] are able to get along with many persons [...], from time to time a storyteller, but never telling too long stories [...].

Negotiating is an important aspect in PA. Participants mentioned various communicative skills that make a difference in negotiations. One participant summarized these as follows:

$\mathrm{He} / \mathrm{she}$ must be able to look for solutions, but also-if necessary-be persuasive, and be able to frame [...] He/ she has the ability to build bridges and maintain them, to selectively inform, to know the difference between being right and proving right [...], including the difference between lying and not telling the whole truth.

Besides the abovementioned competences, participants made clear that the job of a PA professional is all about communication. A broad range of general communicative skills were mentioned. As one of the participants put it, the PA professional should be

[...] a rapid reader [...], a reliable reporter in oral and written language [...], a people's person, male or female, more listening than talking to people, also to "ordinary" people [...] having the power to adapt other interests to a certain extent, looking for support in finding solutions [...] for the regional or local PA professional him/herself and for the decentralized governments he/she is representing in the national and European arena [...] it is important to be a soundboard, to recognize people's interests and opinions, even when these opinions are oppositional. [...] At the end of the day the PA professional should be held accountable for his/her ability to gain support for PA files. That's it.

\section{2 | Attitudinal competences}

Regarding attitudinal competences, two almost paradoxical clusters emerged from the interviews. On the one hand, participants underlined the importance of authentic professionalism ("being who you are"); on the other hand, they stressed the crucial role of flexibility, because circumstances may change at any moment in PA.

With respect to authentic professionalism, almost all participants mentioned loyalty to the home organization and reliability on facts and figures as important characteristics of PA professionals:

They should be open and honest about the home organization and its interests, [...] but at the same time be prudent, discrete, and self-assured, [...] faithful to their message despite objections from others, [...] and always keep their promises.

When a promise nevertheless cannot be kept, "tell it, explain it, be honest, [...] it is of ultimate importance to safeguard your reputation."

Within the political arenas, PA professionals should be able to show independence toward their political surroundings and safeguard their personal integrity and honesty.

$\mathrm{He} / \mathrm{she}$ should be open and honest about personal political opinions, without having personal political goals and ambitions.

Within their home organization, PA professionals must be comfortable with their informal position and willing to work on relationships of mutual respect with officials and colleagues:

Respecting the position, knowledge, and skills of the officials and colleagues is empowering the position of the PA professional in the home organization. [...] He facilitates them [with arena information].

In line with this informal position, PA professionals should be prepared to play a role in the background. At the end of the day, they should be willing to set the stage for the officials, without taking credit for their achievements.

They should not have the urge to personal profiling, by making themselves important and manoeuvring themselves in the spotlight; they should not overshadow officials.

Still, PA professionals must not be afraid to behave "glamorously from time to time." After all, they are the representatives of their home organization in the political arenas, committed to draw attention to the interests of their home organization. They should be known in relevant circles and, for that reason, be extravert.

Finally, PA professionals should have a genuine interest in people and in socializing and have a warm and honest personality:

They should like people, [...] show societal engagement, [...] be sensitive, [...] authentic, [...] accessible [...] dare to show uncertainty, [...] be a pleasant, open and friendly person to talk with, [...] no arrogance.

With respect to flexibility, participants often referred to sudden situational changes in the political dynamics that PA operations are confronted with. Remarkable is the wide range of characteristics that participants mentioned to express the importance of flexibility, without abandoning "who you are." Participants mentioned

Being empathetic and resilient, withstanding stress, having patience, being able to use their antennas for compromising and to operate with speed, but remaining friendly under all circumstances.

At peak moments the PA professional should love to develop short-term PA activities in no time [...] He/she should be a crisis manager. 
Being flexible also refers to the ability to maintain a constructive and positive mood and modus operandi under all circumstances. PA professionals must be able to "accept and endure, and to stay involved in the case, accepting [possible] consequences." From a political perspective, being flexible also means "give and take." In all situations, PA professionals must "know how to behave, be decent and modest, and keep their sense of humor."

The PA professional should be able to avoid problems, know when to keep his/her mouth shut, should not behave like a know-all, be clever, be informal at formal moments, not over-focused [...] accept to not always taste the honor after victory.

Participants mentioned other manifestations of flexibility as well. PA professionals should be neutral and careful not to make quick judgments, should work hard at irregular working hours, and, depending on situation and subject matter, avoid "going where the path may lead, [which means] borderless thinking, up to do fieldwork ... positioning yourself in such a way that personal political affiliations are meaningless."

The PA professional is permanently present in the political arenas, adapting his/her political surroundings but not allowing him/herself to become cocooned, [...] remaining friends despite opposite interests, being able to adjudge the victory to opposite colleagues [...]. The PA professional should have 'female characteristics', like multi-tasking, and being fast in switching between subjects.

\section{3 | Knowledge-related competences}

Participants considered political knowledge and communicative knowledge not as synonyms but emphasized that in their daily work both knowledge domains are intertwined: Functioning in the political arenas is impossible without both knowledge-related competences. Participants said: "Having affinity with regional affairs is having professional knowledge," such as institutional knowledge about political arenas, about the media, and also about the home organization (considered to be an arena as well), is taken for granted, participants argued. "The embedding of PA as policy in the home organization is essential." Being "behind the curtains" as coauthor in political resolutions, arena knowledge is required in all imaginable aspects, such as reading legislative texts, knowing the processes of law making, and knowing that the House of Parliament cannot function without reliable information.

The PA professional must have real interest in political decision-making, [should] follow sent PA messages all day in the national and European arena, [... and ...] internalize mutual connections of political institutions, in the national arena and in the European arena as well [...] Studying European law is discovering that European law-making has its own dynamics. That is why the regional or local PA professional should know the dayto-day practice of working in the European arena.
Participants mentioned various specific elements regarding knowledge-related competences, especially when decentralized governments work on PA files with societal partners (e.g., hospitals, companies, or educational institutes). In such collaborations, regional or local PA professionals may expect their societal colleagues to have comparable knowledge at their disposal. Participants mirrored decentralized PA competences with PA competences of societal partners. PA professionals of societal partners should have the political and institutional knowledge as well; otherwise fruitful collaboration is impossible.

When the region is situated along the border with Germany and/ or Belgium, PA professionals need to know the Euregional facts and figures, and the characteristics of the German and/or Belgian political arenas in Berlin and Brussels as well, and connect this knowledge with their knowledge about the Dutch national and European arena.

Having knowledge about (regional) history, about political processes, about regional projects is essential for regional and local PA. He/she must know the economic facts and figures at the regional level [... which means that ...] the PA professional knows how to manage relevant issues for his/her PA operations.

PA professionals should have all-round knowledge of politics and administration, "even of behavioral rites and rituals in the national arena." Some participants plead that some practical political experience can be very helpful. After all, they should be able to do their work in the political arenas on their own, without the assistance that colleagues may offer each other in the home organization.

$\mathrm{He} / \mathrm{she}$ should be top-notch, the best we have, even better than we [politicians] are, [...] $\mathrm{He} /$ she is not a specialist but a curious generalist with a broad orientation also towards people with opposite views, [...] at least addicted to politics.

\section{5 | DISCUSSION}

In this study, we used the qualitative approach of interviews to investigate the competences required of PA professionals. Our research focused specifically on regional and local PA, which is gaining importance in the governance of municipalities, regions, and provinces in the Netherlands.

On the basis of our interviews, six clusters of competences emerged. In the skills-related competences, we distinguished between political skills and communicative skills. Political skills encompassed all abilities necessary to develop PA strategies and tactics. Many of these skills related to intuition and creative, analytic, and synthetic thinking. Communicative skills covered all abilities that are necessary to get messages across (including framing), to interact effectively, and to build constructive relationships. In the attitudinal competences, we distinguished between dispositions relating to authentic professionalism and dispositions relating to flexibility. There is a potential tension between the two attitudinal competences (being who you are and at the same time being flexible). Authentic professionalism refers to loyalty with the home organization, honesty and openness, suitability 
for the very specific PA role (characterized by having much influence in a largely informal job with vague boundaries, often not in the spotlight), and a genuine interest in people. Flexibility refers to the ability to handle quickly changing environments and circumstances and to keep a positive and constructive mood and approach irrespective of the circumstances. In the knowledge-related competences, we distinguished between political and communicative knowledge (just like in the skills-related cluster). Political knowledge involves the way the political arenas work; communicative knowledge refers to knowledge about media logics and knowledge about PA as a professional discipline.

As such, our findings confirm the multifaceted nature of PA competences, as found in the survey-based study of Figee et al. (2017c). More than that analytical approach and the approaches of other studies in the PR and communication domains (Flynn, 2014; Gregory, 2008; Sha, 2010), however, our study shows that the various competences are often strongly related to each other. This is the case within the six clusters we distinguished and also between different clusters. To give some examples, political and communicative knowledge are strongly interwoven; political skills generally require political knowledge; and many of the communicative skills are strongly connected to the attitudinal competences of authentic professionalism and flexibility. This further complicates the overall picture: Not only do PA professionals have to master a wide variety of competences, but these competences also seem to be interconnected. On the basis of our interviews with PA practitioners and professionals, the competences seem to be far removed from the academic domains that seem to underlie earlier studies (Flynn, 2014; Sha, 2010).

Another important observation is that the field of PA is basically rooted in the academic fields of political science and communication science. Both in the skills-related and in the knowledge-related competences, the two domains are strongly represented. This appears to be a major difference with the related discipline of PR, which is predominantly defined as a communication discipline. Many of the differences between earlier studies into PR competences (Flynn, 2014, Sha, 2010) and our findings may be attributed to this overall difference in disciplinary backgrounds between the two disciplines.

A third observation is that skills appear to be more important than knowledge in the PA profession. This is not to say that knowledge is not important. It is clear that many of the skills described require basic knowledge. For instance, a political antenna without sufficient arena knowledge would add up to little more than a gut feeling or fortunetelling qualities. But our findings underline that-on top of the required knowledge competences-skills deserve a lot of attention.

A final observation involves the prominent role of attitudinal competences. Like the earlier research by McGrath (2006) suggests, personality and disposition of the PA professional are very important. Due to the vague boundaries of the PA discipline, the predominant social aspects of the work, and the dynamics of the context in which the PA professional has to operate, the personal and professional attitudes of the PA professional play an important role. In the attitudinal competences domain, it remains to be seen to what extent the required competences can be learned in professional or academic education or can be traced back to general personality traits of people.
Our findings have several implications for academic PA education. First, it seems recommendable to develop multidisciplinary PA programs, which at the very least incorporate both the fields of political science and communication science. Programs that are rooted in only one of the two disciplines will almost by definition overlook crucial aspects of the discipline. Second, it is important that the attention for knowledge-related competences-which traditionally gets much emphasis in academic educational programs-is sufficiently complemented with attention for skills-related and attitudinal competences. Third, given the complexity and versatility of the PA profession, it seems plausible that the real expertise comes with experience in practice. Therefore, it seems desirable to complement basic academic education with initiatives of continuous education, intervision, and exchange.

Of course, some important limitations of our research must be taken into account. First, our findings are based on the opinions of prolific PA professionals and practitioners. There is no external proof that their views on relevant competences are the real critical success factors for PA professionals. However, we saw quite some convergence in the narratives of the participants, even though they used different formulations. Second, the participants were not triggered to reflect on specific competences, but mentioned the various competences spontaneously. This may be a weakness of the research, as participants may have accidentally forgotten to mention certain competences; it can also be seen as a strength, as the participants were not guided to name any competences. In this respect, the design of our study complements the earlier survey-based study by Figee et al. (2017c). Finally, it should be noted that the numbers of times competence clusters were mentioned may only be somewhat indicative of their weight; our findings should primarily be seen as qualitative results.

In all, our study shows that the PA professional should be a person of many talents. (Subnational) PA is qualified diplomacy, preferable not visible, but certainly serving and always on the spot, requiring a broad spectrum of interrelated competences in skills, attitude, and knowledge, in that order.

\section{REFERENCES}

Davidson, S. (2015). Everywhere and nowhere: Theorising and researching public affairs and lobbying within public relations scholarship. Public Relations Review, 41(5), 615-627.

De Lange, R., \& Linders, P. C. J. (2006). Public affairs as a reality construction: An established paradigm with new implications. Journal of Public Affairs, 6(2), 131-146.

Figee, E. L., Gosselt, J. F., Linders, P., \& De Jong, M. D. T. (2016). Regional public affairs activities in The Netherlands: How to gain ground in the national and European arena. European Urban and Regional Studies. Advance online publication. https://doi.org/10.1177/0969776416674061

Figee, E. L., Gosselt, J. F., Linders, P. C. J., \& De Jong, M. D. T. (2017a). The home front: Internal organization of public affairs in Dutch subnational governments. Journal of Public Affairs. Advance online publication. https://doi.org/101002/pa.1641

Figee, E. L., Gosselt, J. F., Linders, P. C. J., \& De Jong, M. D. T. (2017b). On the battlefield: How Dutch subnational governments together organize public affairs in the national and European arenas. Manuscript submitted for publication. 
Figee, E. L., Gosselt, J. F., Linders, P. C. J., \& De Jong, M. D. T. (2017c). Profiling the public affairs professional: The importance and self-evaluation of PA competences. Manuscript submitted for publication.

Fleisher, C. S. (2007). Developing the public affairs body of knowledge. Journal of Public Affairs, 7, 281-290. https://doi.org/10.1002/PA 268

Flynn, T. (2014). Do they have what it takes? A review of the literature on knowledge, competencies, and skills necessary for twenty-first-century public relations practitioners in Canada. Canadian Journal of Communication, 29, 361-384.

Gregory, A. (2008). Competencies of senior communication practitioners in the UK: An initial study. Public Relations Review, 34(3), 215-223. https://doi.org/10.1016/j.pubrev.2008.04.005

Harris, P., \& Moss, D. (2001a). Understanding public affairs. Journal of Public Affairs, 1(1), 6-8.

Harris, P., \& Moss, D. (2001b). In search of public affairs: A function in search of an identity. Journal of Public Affairs, 1(2), 102-110.

Linders, P. C. J., \& De Lange, R. (2003). Public affairs and werkelijkheidsconstructie [Public affairs and construction of reality]. $\mathrm{PhD}$ dissertation. Enschede, The Netherlands: University of Twente.

Marx, T. G. (1990). Strategic planning for public affairs. Long Range Planning, 23(1), 9-16.

McGrath, C. (2006). The ideal lobbyist: Personal characteristics of effective lobbyists. Journal of Communication Management, 10(1), 67-79.

McGrath, C., Moss, D., \& Harris, P. (2010). The evolving discipline of public affairs. Journal of Public Affairs, 10(4), 335-352. https://doi.org/ 10.1002/PA.369

Noy, C. (2008). Sampling knowledge: The hermeneutics of snowball sampling in qualitative research. International Journal of Social Research Methodology, 11(4), 327-344.

Schuler, D. A. (2002). Public affairs, issues management, and political strategy: Methodological approaches that count. Journal of Public Affairs, 1(4), 336-355.

Sha, B. (2010). Practice analysis: Professional competencies and work categories in public relations today. Public Relations Review, 37(3), 187-196. https://doi.org/10.1016/j.pubrev.2011.04.005

Van de Donk, W. B. H. J. (2014). De centralisatie in openbaar besturen. Over dunne denkramen, pertinente pragmatiek en ambivalente ambities [Centralisation in public administrations. About narrow mindedness, firm pragmatism, and ambivalent ambitions]. $11^{\mathrm{e}}$ lezing Raad Openbaar Bestuur, 12 november 2014 [11th lecture for the Committee of Public Management, the 12th of November 2014].

Van Schendelen, M. P. C. M. (2013). The art of lobbying the EU. More Machiavelli in Brussels. Amsterdam, The Netherlands: University Press.

Edward Figee started his working life in the 1970s as a parliamentary journalist for regional printed media and ended his career in 2011 as regional and local public affairs professional in the Dutch House of Parliament. During his professional life, he was involved in processes decentral governments developed to gain access to the national and European political arenas. These processes are the main topic of his $\mathrm{PhD}$ dissertation, which he defended in 2017 at the University of Twente (The Netherlands).

Jordy Gosselt is an assistant professor of Communication Science at the University of Twente (The Netherlands). The central topic of his research concerns public relations and technology. Based on validated conceptual frameworks in the fields of information systems and communication, including the notion of technology affordances, public relations, and public affairs, he focuses on how organizations may benefit from media relations and public affairs activities in order to enhance their corporate communications with external stakeholders.

Paul Linders worked in various management positions at internationally operating enterprises (AkzoNobel and Sara Lee) and was a senior consultant at an international consultancy group for public affairs and communication. In the 1990s, he was the owner and managing director of two successful agencies for marketing, communication, and fund-raising. Since 2000 , he has been active in higher education at the University of Applied Sciences Utrecht and the University of Twente. In 2016, he was appointed as professor of Governance and Sustainability at the Technological University of the Americas.

Menno de Jong is a full professor of Communication Science at the University of Twente (The Netherlands). His research interests include the domains of organizational and technical communication. Among the research topics he addressed in recent research are public affairs, communication audits, corporate visual identity management, and corporate social responsibility. He was the editor of the Society of Technical Communication's flagship journal Technical Communication between 2009 and 2015.

How to cite this article: Figee EL, Gosselt JF, Linders PCJ, de Jong MDT. Dutch public affairs professionals in the national and European arena: A smart mix of skills, attitude, and knowledge competences. J Public Affairs. 2017;17:e1666. https://doi. org/10.1002/pa.1666 